\title{
Postsaccadic processing of the retinal image during picture scanning
}

\author{
SATOSHI SHIOIRI \\ Chiba University, Chiba, Japan
}

\begin{abstract}
Eye movements were monitored while observers inspected photographs of natural scenes. At the end of each saccade (i.e., at the beginning of each period of steady fixation), the stimulus was replaced for a certain period of time by a uniform field (Experiment 1) or a blurred version of the stimulus scene (Experiment 2). Total fixation duration was measured as a function of the duration of the initial uniform field or the blurred image that followed the saccade. It was found that fixation duration increased proportionally with the duration of the initial replacement field, even for durations as short as $25 \mathrm{msec}$. These results suggest that the visual system uses information on the retina right after each saccade is completed and that the blurred, low-resolution information used in Experiment 2 (cutoff frequency of $0.8 \mathrm{cpd}$ ) is not sufficient for the requirements of picture processing in this task.
\end{abstract}

Eye-movement behavior can be characterized as sequences of saccadic eye movements and the periods between them during which the eyes are steady (fixation period). It has been suggested that each successive image that falls on the retina is subsequently discarded during the next saccade because of saccadic suppression (see reviews by E. Matin, 1974, and Volkmann, 1986) and the masking effects of images seen following saccades (Brooks \& Fuchs, 1975; Brooks, Impelman, \& Lum, 1980; Campbell \& Wurtz, 1978; MacKay, 1970; E. Matin, Clymer, \& L. Matin, 1972). Saccadic suppression is found not only during a saccade, but also, in some cases, until about $100 \mathrm{msec}$ after the beginning of a saccade (50 msec or more after the saccade terminates; e.g., Brooks et al., 1980; Ishida \& Ikeda, 1989; Volkmann, 1986). In other cases, however, rather quick recovery from the suppression has been reported (e.g., Riggs, Volkmann, Moore, \& Ellicot, 1982). The suppression after the end of saccades may indicate that little information is available for visual processing immediately after a saccade.

On the other hand, there are two reasons to suggest that saccadic suppression does not extend beyond the saccade. First, saccadic suppression in terms of the elevation of threshold for detecting briefly presented lights may be so small (often less than 0.7 log unit at maximum; see Volkmann, 1986) that little effect of saccadic suppression should be expected for high-contrast, superthreshold stimuli

This research was supported in part by grants from NIH (EY09258), Canadian Aviation Electronics, NSERC (A8606), and the Ministère de l'Education du Québec to Patrick Cavanagh. The author wishes to thank Terry Williams, at whose laboratory and with whose help the experiments were conducted; Melvin Komoda, for his technical assistance and helpful comments; and Patrick Cavanagh, for his helpful comments. Correspondence should be addressed to $S$. Shioiri, Department of Image Science, Chiba University, 1-33 Yaysi-cho, Chiba, 260, Japan.
(McConkie, Underwood, Zola, \& Wolverton, 1985; Salthouse \& Ellis, 1980). Second, the detection threshold starts to recover soon after the beginning of a saccade, and thus the effect of saccadic suppression quickly diminishes. This is also true for saccadic suppression in other tasks with suprathreshold stimuli (e.g., for detecting image displacement and localization of targets; Bridgeman \& Stark, 1979; Burr, Holt, Jonstone, \& Ross, 1982; L. Matin, E. Matin, \& Pearce, 1969; Shioiri \& Cavanagh, 1989).

The first experiment in the present report examines whether the visual system remains insensitive to retinal input immediately following a saccade. It has often been suggested that a saccade is programmed during the fixation period that precedes it (i.e., direct control of eye movement; Morrison, 1984; Rayner \& Pollatsek, 1981; Vaughan, 1982; see also Inhoff, 1984; McConkie, 1983; Moffitt, 1980; O'Regan, 1979). If this is true, and there is a period of insensitivity after each saccade, programming for the next saccade can only begin following the dead period. Whether there is a dead period at the beginning of each fixation can be determined by inserting a blank stimulus at the beginning of the fixation period and measuring its effect on the total duration of fixation. If, for example, there is a dead period of $50 \mathrm{msec}$ at the beginning of the fixation, a blank stimulus for $50 \mathrm{msec}$ at the beginning should not degrade the observer's performance. In contrast, if the analysis of the retinal image begins right after a saccade, any delay in presenting the full stimulus should lead to longer fixations.

The effect of the stimulus absence has been investigated for a letter-search task (Vaughan, 1982; Vaughan \& Graefe, 1977) and for reading (Ishida \& Ikeda, 1989; Morrison, 1984; Rayner \& Pollatsek, 1981; see also Pollatsek \& Rayner, 1982; Rayner, 1983; Rayner, Inhoff, Morrison, Slowiaczek, \& Bertera, 1981; Rayner, Slowiaczek, Clifton, \& Bertera, 1983; Wolverton \& Zola, 1983). Some of the experiments showed results that are 
consistent with a dead period right after each saccade (Ishida \& Ikeda, 1989; Vaughan, 1982; Vaughan \& Graefe, 1977). In Vaughan's (1982) experiment, the observers searched for a target letter while they alternated the point of fixation between two spots where either a nontarget letter or the target letter was presented with various delays after the end of each saccade (stimulus onset delay, or SOD). Vaughan's results showed that fixation duration was constant when SOD was shorter than about $60 \mathrm{msec}$. Similarly, Ishida and Ikeda showed that replacement of stimulus text by a visual mask for about $30 \mathrm{msec}$ at the beginning of each fixation had little effect on reading speed.

On the other hand, some of the other experiments showed that the stimulus absence at the beginning of fixation degraded reading performance (Morrison, 1984; Rayner \& Pollatsek, 1981). Rayner and Pollatsek used a visual mask to delay the onset of the stimulus presentation. They found that fixation duration was prolonged, even when the stimulus onset was delayed for as little as $25 \mathrm{msec}$

Although all these results showed that SODs longer than $100 \mathrm{msec}$ influence observers' performance, there is a discrepancy among the experiments concerning the effects of short SODs. There are many differences in conditions among these experiments, which may account for the difference in results. Two important factors are the stimulus and the task. Previous experiments used stimuli and tasks for which observers made eye movements in a relatively restricted manner. For example, Vaughan (1982) asked the observers to make saccades between two spots. In the reading experiments, the eye-movement pattern is also restricted, but in a different way. The direction of saccades is normally left to right, and the distance of each saccade is relatively consistent. Since the focus of the present report is on the effect of SOD in more general conditions, photographs of natural scenes were used as stimuli. Observers could saccade freely over each stimulus.

A slightly different issue was addressed in the second experiment. This experiment examined whether lowresolution information might be more useful than detailed, high-resolution information at the beginning of fixation. It has been shown that global features or low-resolution information of stimulus figures are processed earlier than or prior to local information (Navon, 1977; Navon \& Norman, 1983). Navon used a large letter that was made out of small letters as a stimulus (small letters were arranged to construct a large letter), and he found that the observers named the large letters more quickly than the small ones. For programing of eye movements, it has been reported that saccades are often directed to the center of gravity of two spatially separated targets, that is, a global feature of the stimulus (Coren \& Hoenig, 1972; Findlay, 1982; Ottes, Van Gisbergen, \& Eggermont, 1984, 1985). This effect, labeled the global, or averaging, effect of saccades, is seen for quite large separations (sometimes larger than $10^{\circ}$ of visual angle), and it occurs most frequently for saccades with short latency. The saccade programming system seems sometimes to use only coarse information, much coarser than the acuity limit. This is also consistent with the results of Shioiri and Ikeda (1989), which showed that information coarser than the acuity limit is sufficient in the periphery for picture scanning. These results suggest that global features (low spatial frequencies) might be processed early in the fixation period at any locus of visual field, including the fovea (i.e., coarse-to-fine processing).

In Experiment 2, a blurred version of the scene was inserted at the beginning of each fixation period instead of a uniform field. This replacement delayed the onset of high-resolution information of the stimulus images. Three predictions were possible for the fixation-duration measurement. First, the absence of high-resolution information may not affect the visual processing at the beginning of each fixation, suggesting that the visual system initially processes only global information. Second, the absence of high-resolution information may degrade performance just as much as the absence of the whole stimulus (replacement by the uniform field), suggesting that the visual system requires local information at the beginning of fixation. Finally, the absence of high-resolution information may influence processing, but less than the absence of the whole stimulus, suggesting that both global and local features are processed from the start.

\section{METHOD}

Eye movements were monitored while an observer was inspecting a photograph of a natural scene that was projected on a screen. The stimulus was replaced briefly by a uniform field (Experiment 1) or a blurred image of the stimulus (Experiment 2) for a variable duration after the end of each saccade (SOD), as shown in Figure 1. An experimental session consisted of the inspection of 50 stimulus scenes. A recognition test followed the experimental session in order to keep the observer's attention on gathering information of the stimulus throughout its presentation. The observers were instructed to memorize scenes presented in the experimental session so that they could select these scenes among unseen photographs (distractors) in the following recognition test.

\section{Apparatus}

The apparatus is illustrated schematically in Figure 2. Stimuli were $35-\mathrm{mm}$ color slides projected on a screen from the back. The screen was located $70 \mathrm{~cm}$ in front of the observer, and the stimulus size was $25^{\circ} \times 25^{\circ}$ in visual angle. The beam from the projector was split into two optical channels by a beam splitter. Each optical channel was composed of a set of lenses, a liquid crystal shutter, a mechanical shutter, and an aperture. The image through the first optical channel was focused on the screen as the stimulus. The second channel was used to produce a pseudo-uniform field (in Experiment 1) or a blurred low-resolution image (in Experiment 2) by defocusing. The two optical channels were aligned so that the two images from the channels on the screen could be superimposed accurately when they were both projected in focus.

The liquid crystal shutters always worked in such a manner that one opened and the other closed simultaneously, exchanging the images on the screen without any blank interval. Both the opening and closing of the shutter were completed within $5 \mathrm{msec}$. The me- 


\section{Eye movement}

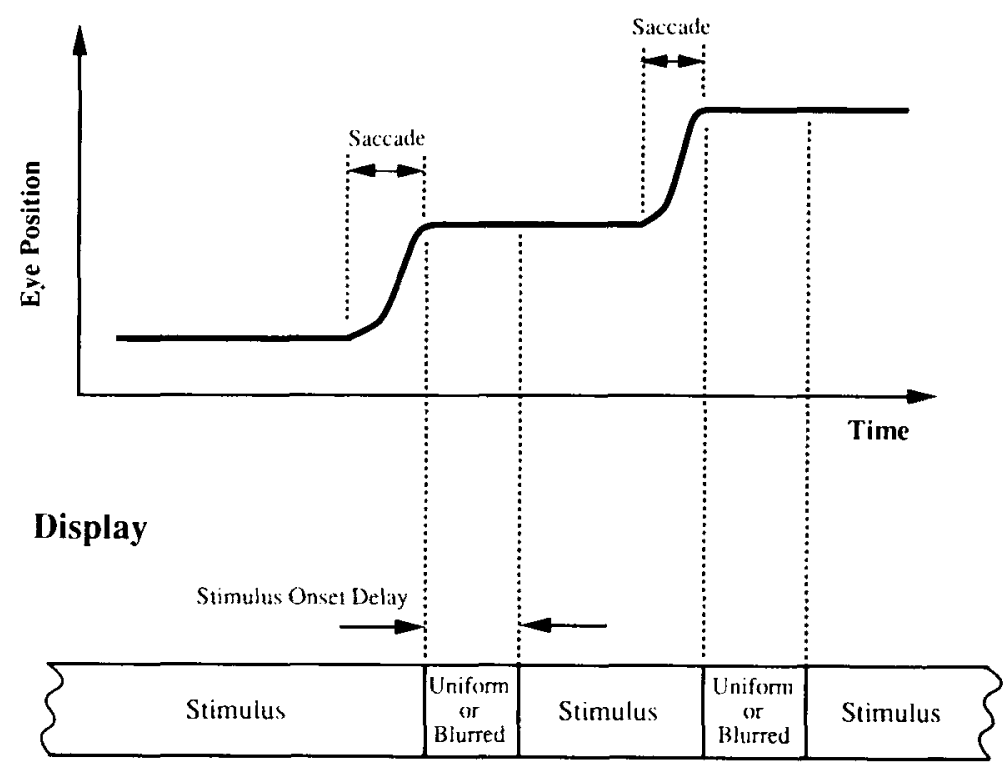

Figure 1. Schematic view of the experimental paradigm. The stimulus scene is replaced by the uniform field or the blurred, low-resolution image at the end of each saccade and the stimulus returns anter a given period of absence (stimulus onset delay).

chanical shutter, which worked rather slowly $(25 \mathrm{msec})$, was used to start and to terminate the presentation of the stimulus by opening and closing the two channels together. All the shutters and the advance of the slides were under computer control.

The horizontal and vertical components of eye movements were monitored by an eyetracker developed by Eizenman, Frecker, \& Hallett (1984). The eyetracker detected the center of the corneal reflected image of an infrared light source. A microcomputer sampled signals from the eyetracker every $1 \mathrm{msec}$. The velocity of eye movements was computed from the difference between the present eye position and the one measured $4 \mathrm{msec}$ before. The moment at which the velocity exceeded $40^{\circ}$ per second was adopted as the onset of a saccade. After the detection of its onset, the saccade was regarded as being in progress while the velocity was greater than $30^{\circ}$ per second. The observers bit their dental impressions to keep their heads steady and viewed the screen with their right eyes.

Spatial resolution of the eyetracker was better than 1 min (Eizenman et al., 1984), and its temporal resolution was $1 \mathrm{msec}(1000 \mathrm{~Hz}$ sampling rate). The accuracy of the eye-position measurement was examined for each observer before the experiments. The observers followed a laser spot that moved around randomly among the points of an $11 \times 11$ matrix that covered a $30^{\circ}$ square field. The average error of eyetracker measurement following calibration was $0.4^{\circ}$ for the horizontal component and $0.5^{\circ}$ for the vertical component.

Uniform and blurred images. To produce a pseudo-uniform field (used in Experiment 1), the image through the second channel was greatly defocused. The degree of defocusing was determined by the contrast threshold of a horizontal square-wave grating (contrast of $96 \%$ ) of 0.1 cycles per degree (cpd) ( 2.5 cycles per image) with the first channel closed. The position of the lens for focusing in the second channel was adjusted so that the grating was just under threshold, or just became invisible (the observer was the author). This defocusing removed spatial-frequency components higher than $0.1 \mathrm{cpd}$ and produced a practically uniform field for most of the stimulus scenes. Although gradual change in luminance and color remained across the screen for some scenes, no information of the content of the scene was available.

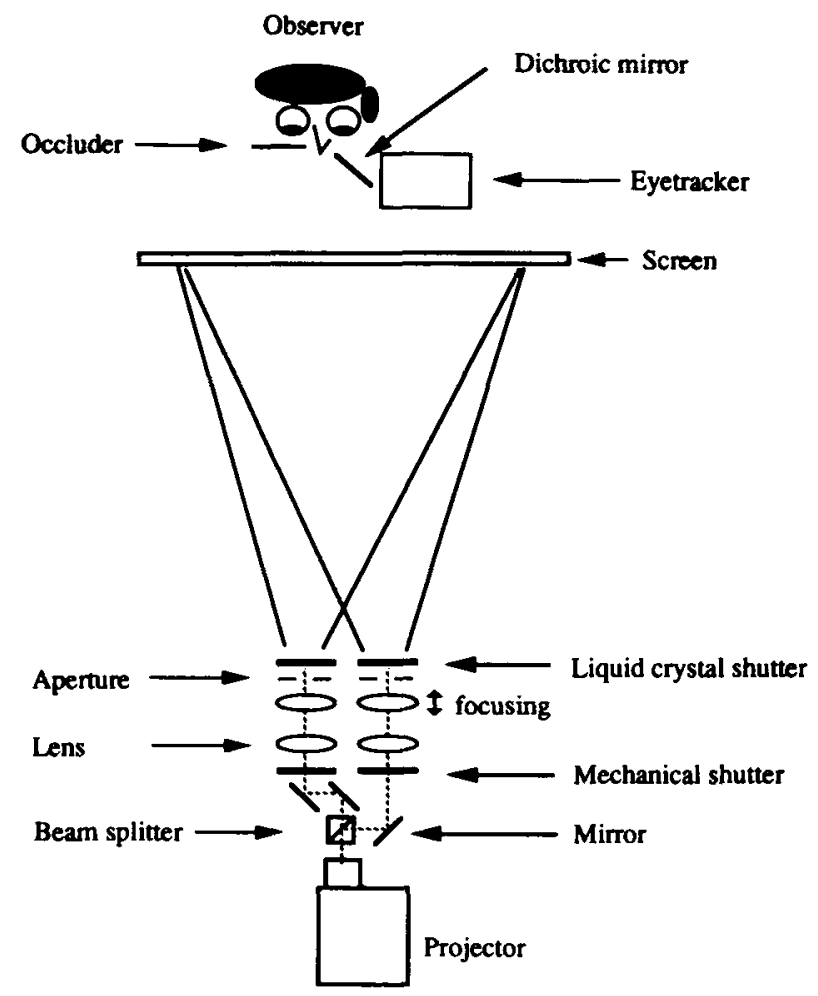

Figure 2. Diagram of the apparatus used in the experiments. The light beam from the projector was divided into two optical channels: one for the stimulus in focus, and the other either for the pseudouniform field or for the blurred image. One of the lenses in each channel was used to focus or defocus the image on the screen. The eyetracker was located above the observer in the real setup, but is shown here beside the observer for clarity. 
The blurring in Experiment 2 was also achieved by defocusing the stimulus. The grating of $0.8 \mathrm{cpd}$ ( 20 cycles per image) was used for the adjustment to remove spatial-frequency components higher than $0.8 \mathrm{cpd}$ The cutoff spatial frequency was set so that the observers would obtain global information of the scenes (most scenes could be identified by name, such as a mountain or a beach, after blurring), but the lack of detail was clearly evident. The blurred images also had sufficient information for a global effect of the saccades, since the effect occurs for up to $10^{\circ}$ separation of two tar gets. It would be expected that presenting the blurred image at the beginning of fixation facilitates visual processing, at least to some degree, in comparison with presenting the uniform field if global features tend to be processed prior to local features (so that a highresolution image is not required at the beginning of fixation).

Since defocusing of the image also reduced the luminance on the screen, the aperture size of the first optical channel was adjusted to equate its average luminance to that of the second channel. Approximately matched mean luminance was obtained on the three types of projection (the uniform field, the blurred image, and the stimulus in focus) for all scenes (about $0.5 \mathrm{~cd} / \mathrm{m}^{2}$ ).

\section{Stimuli}

Color photographs of natural scenes were used as stimuli. They included mountains, forests, fields, beaches, waterfalls, and houses, but neither persons nor other animate objects appeared. Two hundred scenes were gathered from magazine photographs and divided into four groups of $\mathbf{5 0}$ scenes. Two of the four groups were used in Experiment 1, and the other two were used in Experiment 2. In each experiment, one of the two groups was used as stimuli and the other was used as distractors.

Each stimulus set was divided into five subsets of 10 scenes. This division into subsets was at random, but with the restriction that the numbers of four different kinds of scenes (mountains, forests, beaches, and the others) were kept constant across subsets, minimizing the possible influence from the difference in contents.

\section{Procedure}

In the learning phase of the experiment, the observer was instructed to inspect each scene to identify it in the recognition test afterward. The learning phase contained 50 trials of stimulus presentations for $5 \mathrm{sec}$ each. In each trial, mechanical shutters opened to present a stimulus image when the computer confirmed that the observer was fixating the center of the screen (within $0.5^{\circ}$ error), where a laser spot was presented in the dark between trials. During the presentation, the stimulus image on the screen was replaced for a given period after each saccade by the uniform field (Experiment 1 ) or the blurred image (Experiment 2). After presentation of the 50 stimulus scenes, the recognition phase followed. In the recognition phase, 100 scenes were presented one after another (50 stimulus scenes and 50 previously unseen distractor scenes), and the observers decided whether a scene had been presented in the experimental session by responding "yes" or "no." There was no replacement of the image by uniform or blurred initial intervals in the recognition phase, and the presentation of each scene lasted until the observer responded. The readings of the eye positions were saved on the hard diskette of the microcomputer.

Stimulus onset delay in the learning phase was either $0,25,50$, 100 , or $200 \mathrm{msec}(0 \mathrm{msec}$ SOD was the control condition, in which no replacement of image occurred). Stimulus onset delay varied randomly from trial to trial, but the same SOD was used for all fixation periods throughout the $5 \mathrm{sec}$ of stimulus presentation in a given trial. For each SOD, 10 trials were performed by each observer, using one of the five subsets of a stimulus set. Each of the subsets was presented with different SODs for different observers so that each scene would be used once in each SOD condition.

Eyeblinks were identified by visual inspection of the eyemovement records after the experiment in order to discard eye- fixation data with blinks from the analysis. This is because blinks could trigger the exchange of images as well as saccades. In addition, an arbitrary minimum of $50 \mathrm{msec}$ was set for a fixation, and a period shorter than $50 \mathrm{msec}$ between two saccades was regarded as too short to be a fixation in analysis.

\section{Observers}

One female and 4 male observers who had normal acuity participated in the experiments. None of them were aware of the purpose of the experiment.

\section{RESULTS}

\section{Replacement by Uniform Field}

Figure 3 shows the average of the median fixation duration over all 5 observers as a function of SOD in Experiment 1 . The average numbers of fixations used for the analysis were $94.0,86.4,78.6,67.0$, and 60.2 for 0-, 25-, 50-, 100-, and 200-msec SODs, respectively.

In Figure 3, fixation duration increases monotonically with the increase of SOD, showing that fixation duration was prolonged by all SODs, including the shortest SOD of $25 \mathrm{msec}$. The onset of the following saccade was delayed when no information was available at the beginning of fixation. This suggests that retinal information is useful for picture scanning at the beginning of the fixation, agreeing with the results for reading of Rayner and Pollatsek (1981) and Morrison (1984). Furthermore, the slope of the best fitted line $(0.78)$ is close to 1.0 , suggesting that fixation duration is prolonged about the same duration of SOD. This may indicate that the visual system requires a relatively constant duration of stimulus presentation for each fixation, independently of the onset of the stimulus. Note that no statistical test was performed to examine whether the slope differed from 1.0 , because the shape of the distribution function of fixation duration varied so dramatically as a function of SOD that it is obvious that linear prediction is not appropriate (see Figure 5).

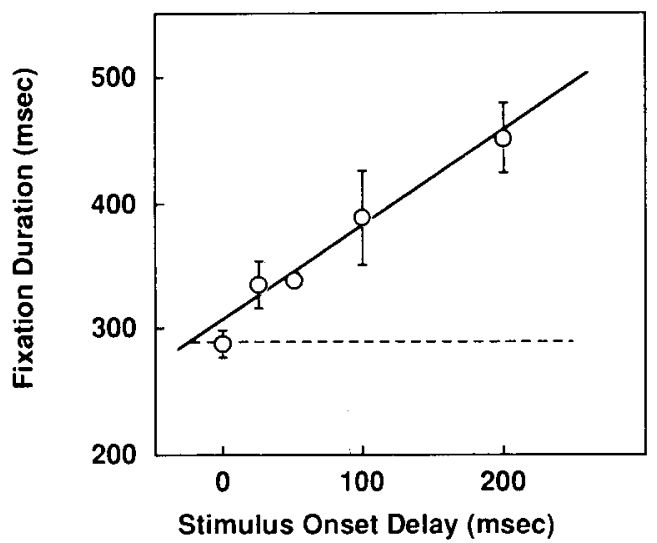

Figure 3. Median fixation duration as a function of stimulus onset delay in Experiment 1. The error bars represent standard errors across observers. The solid line shows the best fitted linear function by the least squares method. The dashed line represents the median fixation duration in the recognition test. 


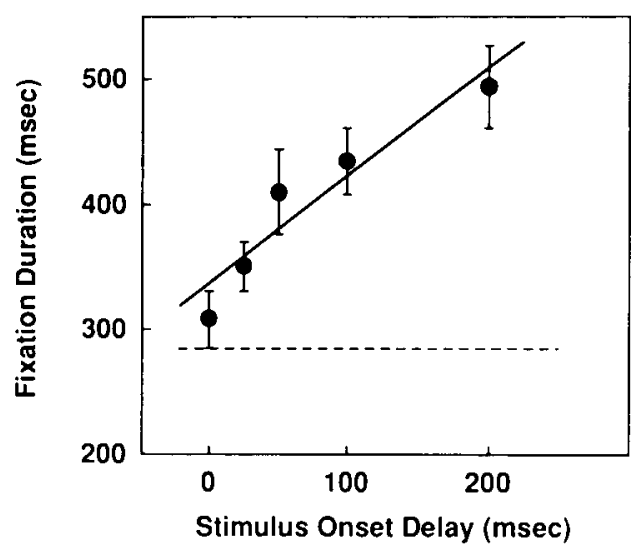

Figure 4. Median fixation duration as a function of stimulus onset delay in Experiment 2. The error bars represent standard errors across observers. The solid line shows the best fitted linear function by the least squares method. The dashed line represents the median fixation duration in the recognition test.

\section{Replacement by Blurred Image}

Figure 4 shows the average of the median of fixation duration as a function of SOD in Experiment 2. The average numbers of fixations used for the analysis were 99.6, $83.6,79.0,72.8$, and 63.2 for $0-, 25-, 50-, 100-$, or 200 msec SODs, respectively.

The results in Experiment 2 are almost identical to those in Experiment 1. Fixation duration increases with the increase of SOD, and the slope of the fitted line $(0.87)$ is close to 1.0. Presenting the blurred image at the beginning of each fixation did not change the effect of SOD. No shortening of fixation duration (or facilitation of the saccade) due to the blurred image was found. This suggests that high-resolution information (above $0.8 \mathrm{cpd}$ or 20 cycles per image) is required for visual processing, even immediately after a saccade.

An alternative explanation, however, may apply. The observers reported that they saw transient changes on the screen except when the SOD was $0 \mathrm{msec}$. For longer SODs, they saw the blurred image before the stimulus. They noticed temporal inhomogeneity in the stimulus, even for the SODs for which the blurred image could hardly be seen (25- and 50-msec SODs). This transient event may have influenced the programming of saccades. It has been suggested that a visual event that occurs at the fovea delays the initiation of a saccade that has been programmed (L. E. Ross \& S. M. Ross, 1980; S. M. Ross \& L. E. Ross, 1981). L. E. Ross and S. M. Ross (1980) showed that the latency of saccades directed to a target in periphery was prolonged when a foveal stimulus was presented up to $150 \mathrm{msec}$ after the onset of the target. It seems reasonable that the visual system might cancel a saccade in order to keep fixating when new information is found at the foveal region. In the present experiment, it may have been that detection of the exchange of images on the screen delayed the onset of saccades that had been programmed, prolonging fixation duration accordingly. The monotonic increase of fixation duration with the increase of SOD could result even if some saccades were programmed while the blurred image was being presented.

However, an analysis showed that the prolongation of saccade latency reported by L. E. Ross and S. M. Ross (1980) and S. M. Ross and L. E. Ross (1981) is not large enough to explain the present results. The transient event prolonged saccade latencies by at most $50 \mathrm{msec}$, even when the event occurred $150 \mathrm{msec}$ after the beginning of the fixation period. Since the effect of SOD is sometimes close to $200 \mathrm{msec}$ in the present experiment, the results cannot be attributed solely to the effect of transient events. The effect of transient events, however, could vary in experimental conditions, and it may be inappropriate for the evaluation of the effect in the present experiment to use the results from different conditions. To evaluate the pure effect of delay of stimulus presentation, further investigation with a technique to distinguish the effect of stimulus delay from the accompanying transient event is required.

\section{Distribution Function of Fixation Duration}

The results of Experiments 1 and 2 suggest that the mean fixation duration increased approximately in proportion to the SOD. However, the distribution function of fixation durations reveals a more complex picture.

Figure 5 shows the frequency of eye fixations as a function of their duration (data pooled over all observers, since similar, though more variable, distribution functions were obtained from each individual). The left panels show results for the uniform-field condition (Experiment 1), and the right panels show results for the blurred-image condition (Experiment 2). The frequency of the fixation duration was obtained by pooling data in 50-msec bins, up to $1,000 \mathrm{msec}$. Although some fixations were longer than $1,000 \mathrm{msec}$ for long SODs $(4.2 \%$ and $7.3 \%$ for $100 \mathrm{msec}$ and $200 \mathrm{msec}$, respectively, in Experiment 1;0.0\% and $6.0 \%$ in Experiment 2), they are not distributed in any systematic manner.

One can see in Figure 5 that the distribution does not vary in any simple manner with SOD in both conditions, although the fixation duration increases on average with the increase of SOD. The fixation-duration distribution could be characterized by a single-peak function only for 0 -msec SOD in the uniform condition, whereas more than one peak is seen for the others. For the longest SOD $(200 \mathrm{msec}$ ), four peaks are seen in both conditions. (Multiple peaks are also seen in Figure 3 of Morrison, 1984, but for a reading task.)

A closer look at Figure 5 shows that the earliest peak or shoulder of the function occurs at around $100 \mathrm{msec}$ for all SODs, and the frequency there is similar (between $5 \%$ and $8 \%$ ). These earliest saccades do not seem to be affected by SOD. To make this point clearer, Figure 6 shows the frequency of fixation with the duration of less than $150 \mathrm{msec}$ as a function of SOD. Fixations with durations of less than $350 \mathrm{msec}$ are shown for comparison. 


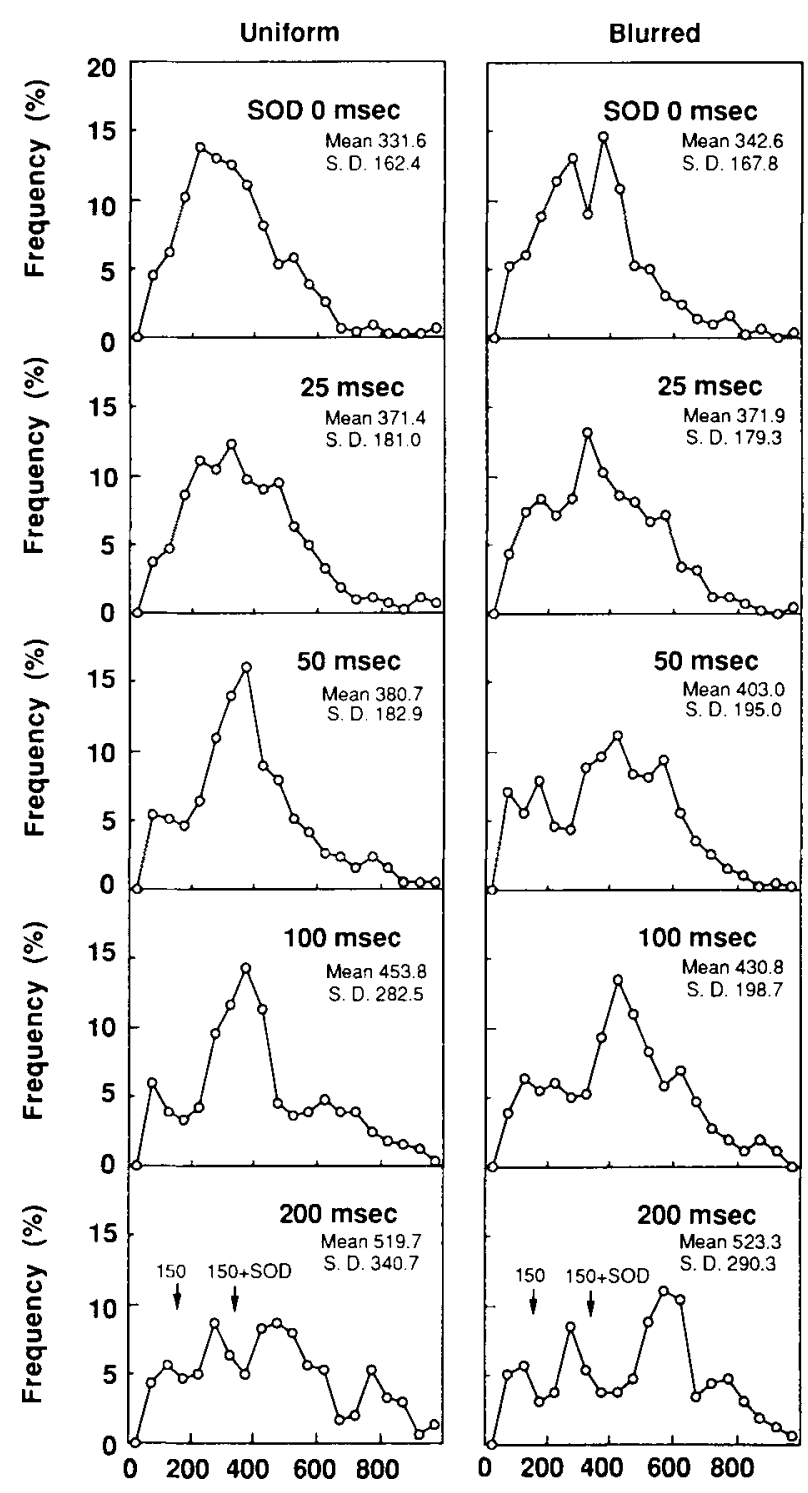

Fixation Duration (msec)

Figure 5. Distribution functions of fixation duration. Frequency of occurrence is calculated for each 50 -msec bin. In the panels for $200-$ msec stimulus onset delay, the arrows labeled "150" indicate fixation durations of $150 \mathrm{msec}$, and the arrows labeled "150+SOD" indicate fixation durations of $\mathbf{3 5 0} \mathbf{m s e c}$ (see text).

For both the uniform and blurred conditions, the frequency of fixations shorter than $150 \mathrm{msec}$ was approximately constant for all SODs, whereas the frequency of fixations shorter than $350 \mathrm{msec}$ decreases with SOD (i.e., the number of fixations with durations longer than $350 \mathrm{msec}$ increases). This analysis suggests that saccades that follow short duration fixations (less than $150 \mathrm{msec}$ ) are programmed without any influence from the retinal image during the current fixation.

Fixations with unusually short durations are known to be followed by a corrective saccade, which is a small saccade that automatically follows a saccade that has failed to land accurately. Short fixation durations in the present experiments, therefore, may have been a result of corrective saccades. Saccade length was analyzed to examine whether fixations with short duration were followed by small-corrective-saccades. Since the length of corrective saccades is about $10 \%$ of that of preceding saccades (e.g., Henson, 1979; Weber \& Daroff, 1971, 1972), the length of a saccade with short latency will be much smaller than the others if the saccade is a corrective saccade. The analysis showed that the mean saccade length (calculated by averaging over all data from the two experiments) is $5.5^{\circ}$ for the saccades following fixations shorter than $150 \mathrm{msec}$ and $6.4^{\circ}$ for the saccades following fixations longer than $150 \mathrm{msec}$. This indicates that short fixation duration cannot be attributed to corrective saccades, although the data possibly include corrective saccades in some proportion.

There are three possible interpretations for there being no effect on shorter fixation by SOD. First, saccades with short duration of fixation may be programmed by a different mechanism from the one that programs saccades with longer fixation duration. There are arguments that the visual system has two different pathways for controlling eye movements (Bouma \& de Voogd, 1974; Malt \& Seamon, 1978; Ottes et al., 1984, 1985; Salthouse \& Ellis, 1980). Saccades can be controlled by high-level processes involved in picture recognition (Antes, 1974; Loftus \& Mackworth, 1978; Mackworth \& Morandi, 1967), letter identification (Salthouse \& Ellis, 1980), and sentence comprehension (Inhoff, 1984; Klein \& Kurkowski, 1974; Moffitt, 1980; O'Regan, 1979; Rayner, $1975,1977)$. In contrast, there is a reflexive system that programs saccades independently of image understanding or reading (Bouma \& de Voogd, 1974; Malt \& Seamon, 1978; Ottes et al., 1985). Since the former probably requires longer time than the latter, saccades with short fix-

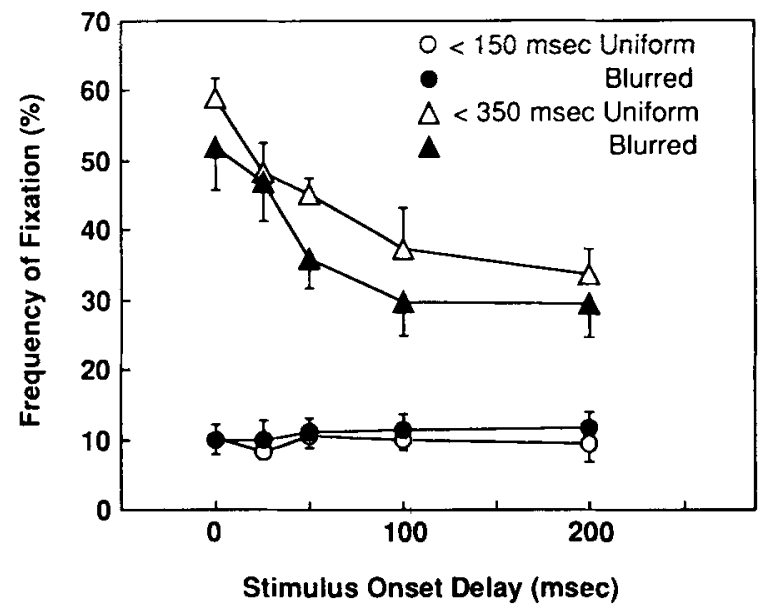

Figure 6. Percentage of fixations whose duration is shorter than 150 msec (circles) and 350 msec (triangles) as a function of stimulus onset delay. Open symbols represent the results for the uniformfield condition (Experiment 1), and filled symbols represent the results for the blurred-image condition (Experiment 2). The error bars represent standard errors across observers. 
ation might be controlled by the reflexive process and saccades with longer fixation might be controlled by higher processes.

Second, the lack of effect of SOD on the briefer fixation durations may be related to the minimum latency of saccade programming. The latency from the presentation of a target to the onset of the response saccade is normally longer than $150 \mathrm{msec}$ (e.g., Hallett, 1978; Hallett \& Lightstone, 1976; Ottes et al., 1985; but see below about express saccades). If we assume that the minimum duration to program a saccade is $150 \mathrm{msec}$ from the onset of a target, a saccade that follows a fixation with a duration shorter than $150 \mathrm{msec}$ cannot be influenced by any information at the fixation; thus, no effect of SOD will be expected. This assumption also implies that the programming of saccades that follow fixations shorter than $150 \mathrm{msec}$ starts before the end of the previous saccade. This implication is consistent with the results for doublestep stimuli (Becker \& Jürgens, 1979; Komoda, Festinger, Phillips, Duckman, \& Young, 1973; Levy-Schoen \& Blanc-Garin, 1974; Ottes et al., 1984; van Asten, Gielen, \& de Winkel, 1988; Wheeless, Boynton, \& Cohen, 1966). In these experiments, two target steps occurred in succession with a time separation between the steps such that the second step occurred before the observer completed the saccade to the first step. The duration of the fixation period between the two saccades was shorter than the normal saccade latency (less than $150 \mathrm{msec}$ ) when the second step occurred with a very short delay after the first one.

On the assumption that a minimum of $150 \mathrm{msec}$ is required to program a saccade, any change in the stimulus should affect fixation durations longer than $150 \mathrm{msec}$. The saccades following fixations of between $150 \mathrm{msec}$ and $\mathrm{SOD}+150 \mathrm{msec}$ possibly reflected programming based on the information in the uniform field (Experiment 1) or the blurred image (Experiment 2), whereas saccades that occurred after SOD+150 msec were probably based on the processing of the clear, focused image. In the panels for $200 \mathrm{msec}$ SOD in Figure 5, the arrows indicate the points of SOD (200 msec) and SOD + $150 \mathrm{msec}(350 \mathrm{msec})$. Interestingly, the second peak of the distribution function is between the two arrows, and the third peak is at durations longer than SOD $+150 \mathrm{msec}$ in both conditions. Saccades, therefore, appear to be divided into three groups: those programmed without any information from the current fixation, those based on information from the uniform field or the blurred image, and those based on the processing of the clear stimulus image.

Third, it may be that the short fixation because of attention shifts prior to the beginning of the current fixation resulted in no effect of SOD. It is possible that the observer has already processed the information required from the current fixation before he/she even got there. If all the necessary information from the target location could be extracted in peripheral vision, it might have been acquired after the saccade to the location had been programmed but before the saccade began (or perhaps during the saccade). If the observer's attention shifts from the initial goal of the saccade before the saccade is com- pleted, the visual system can begin to program the subsequent saccade to the new point of attention soon after (or even before) the end of the previous saccade. As doublestep-target experiments showed, changing the goal of a saccade before the saccade is completed can result in very short durations of the subsequent fixation (see similar discussion in Morrison, 1984). Several authors have discussed similar ideas concerning attention shifts in the case of express saccades, that is, saccades with latencies as short as about 100 msec (Fischer \& Boch, 1983; Fischer \& Breitmeyer, 1987; Fischer \& Ramsperger, 1984).

\section{Fixation Durations Greater Than 150 Msec}

The analysis of the distribution of fixation durations suggests that some of the saccades are not affected by SOD. This somewhat negates the assumption that information processing during the current fixations controls the next saccade. Thus, fixation data was reanalyzed without fixations shorter than $150 \mathrm{msec}$. Figure 7 shows medians of fixation durations obtained without the shorter fixations. The results are consistent with those shown in Figures 3 and 4; the fixation duration becomes longer in proportion to the SOD. While the slope of the fitted line is closer to $1.0(0.80$ for the uniform condition and 0.94 for blurred condition) than those of the previous analyses, the results can be summarized as being generally similar to those with the shorter fixations included.

\section{Recognition Rate}

The percentage of hits and false alarms in the recognition test are shown in Table 1. The percentage of hits is between $60 \%$ and $85 \%$ for all cases, suggesting that the task was appropriate to keep the observers' attention on the stimulus throughout the presentation in each trial.

Table 1 shows that the hit rate tends to decrease with the increase in SOD. It has been suggested that one of the important factors that controls recognition memory

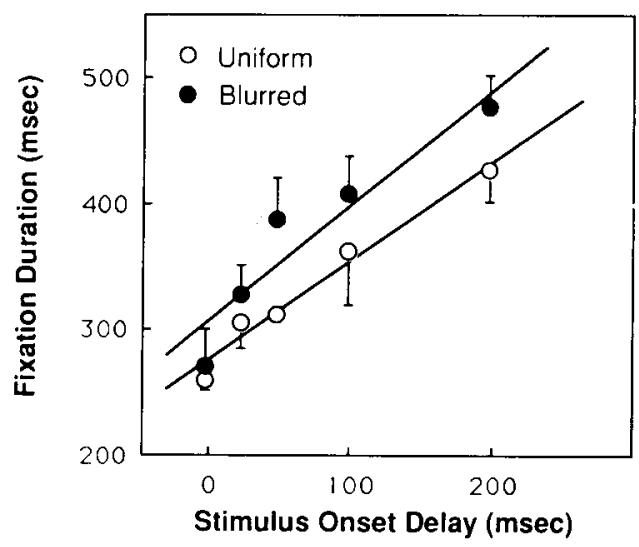

Figure 7. Median fixation duration without fixations shorter than 150 msec as a function of stimulus onset delay. Open circles represent the results for the uniform-field condition (Experiment 1), and filled circles represent the results for the blurred-image condition (Experiment 2). Each of the solid lines shows the best fitted linear function. The error bars represent standard errors across observers. 
Table 1

Results of Recognition Tests and Numbers of Fixations

\begin{tabular}{|c|c|c|c|c|c|c|}
\hline & \multicolumn{5}{|c|}{$\begin{array}{c}\text { Stimulus Onset Delay } \\
\text { (in Milliseconds) }\end{array}$} & \multirow{2}{*}{$\begin{array}{l}\text { False } \\
\text { Alarm }\end{array}$} \\
\hline & 0 & 25 & 50 & 100 & 200 & \\
\hline \multicolumn{7}{|c|}{ Experiment 1} \\
\hline Hits (percent) & 72.0 & 78.0 & 70.0 & 74.0 & 62.0 & 16.4 \\
\hline Fixations* & 9.4 & 8.6 & 7.9 & 6.7 & 6.0 & \\
\hline \multicolumn{7}{|c|}{ Experiment 2} \\
\hline Hits (percent) & 84.0 & 70.0 & 72.0 & 68.0 & 64.0 & 7.2 \\
\hline Fixations* & 10.0 & 8.4 & 7.9 & 7.3 & 6.3 & \\
\hline
\end{tabular}

*Number per scene

is the number of fixations (Loftus, 1972). The present data also show that the average number of fixations during each trial decreased with SOD, as shown in Table 1, and the correlation coefficient between hit rate and number of fixations is fairly high ( 0.80 for all 10 sets of data in Table 1). The result, however, cannot distinguish between the effect of fixation number and presentation duration, since the total duration of stimulus presentation decreased as SOD increased. The worse performance for longer SOD can be interpreted as resulting from fewer fixations and/or shorter duration of stimulus availability.

\section{DISCUSSION}

Experiment 1 showed that the duration of the fixation period was prolonged by the absence of information at the beginning of the fixation. The fixation duration monotonically increased with the duration of the absence, or stimulus onset delay. A similar result was found in the second experiment, in which only a blurred, lowresolution image was presented at the beginning of fixation. The blurred image did not facilitate the onset of saccades. These results suggest that the visual system uses information right after (at least $25 \mathrm{msec}$ or longer) the end of saccades and that the information in the blurred image used in the present experiment $(20$ cycles per image or $0.8 \mathrm{cpd}$ of cutoff frequency) is not sufficient for processing.

The results from the present experiments agree with those of Rayner and Pollatsek (1981) and Morrison (1984), despite the possible difference in the strategy of eye scanning for different types of stimulus (Loftus, 1983; Rayner, 1978). Prolongation of fixation duration by SOD occurs in widespread situations. This is consistent with the claim that observers can extract information at very early stages of fixation for programming eye movement during reading (Rayner et al., 1981).

On the other hand, some authors (Ishida \& Ikeda, 1989; Vaughan, 1982) have reported that fixation duration does not vary with SOD. Ishida and Ikeda showed that a brief mask did not influence reading speed. However, their mask did prolong reading time when it was visible, suggesting that the detection of the exchange of images on the screen may be critical for the effectiveness of the mask. Since in the present experiments the presentation of the uniform field and the blurred images could be noticed even for the shortest SOD, the prolongation of fixation duration observed here for all SODs is consistent with the results of Ishida and Ikeda. Vaughan showed that at short SODs, fixation duration was independent of SOD. One difference between Vaughan's study and the present experiments is that there were only two points to fixate in Vaughan's visual search, whereas our observers fixated many positions on a stimulus during picture scanning. In Vaughan's visual search, it may have been sufficient to decide only the time to initiate the saccade, since its goal was always known. In contrast, in the present experiments, a new goal had to be identified for each successive saccade. Since perhaps more information is required to program a saccade for scanning scenes than in Vaughan's visual search, the visual system may be more sensitive to the lack of information in this case.

In Experiment 2, the stimulus was replaced by a blurred, low-resolution image. Since global information in a figure is often thought to be processed earlier than details (global precedence; Navon, 1977; Navon \& Norman, 1983) and since saccades are sometimes controlled by only coarse information in a stimulus, especially when saccadic latency is short (global effect of saccade; Coren \& Hoenig, 1972; Findlay, 1982; Ottes et al., 1984, 1985), one prediction was that the presentation of the blurred image at the beginning of fixation might be sufficient to determine the next point of fixation. The results showed, however, that the presence of the low-resolution image provided similar prolongation of fixation duration, as did the uniform field. Local feature or high-resolution information appears to be required even immediately after the end of the saccade, providing there is no evidence of global precedence or coarse-to-fine processing. However, two points remain for future investigation on this issue. First, it is not clear how the transient change on the screen influenced the fixation duration. It is important to measure the effect of a brief transient (say, a 5-msec insertion of a blank field) at various delays during the presentation of the clear stimulus image. Second, the conclusion from Experiment 2 is rather restricted since only one cutoff frequency for blurring was used. Although the cutoff frequency of $0.8 \mathrm{cpd}$ is appropriate for the purpose of Experiment 2, systematic change of cutoff frequency will be required to explore coarse-to-fine processing in general.

\section{REFERENCES}

ANTES, J. R. (1974). The time course of picture viewing. Journal of Experimental Psychology, 103, 62-70.

BECKER, W., \& JüRGENS, R. (1979). An analysis of the saccadic system by means of double step stimuli. Vision Research, 18, 967-983.

Bouma, H., \& DE VoOGD, A. H. (1974). On the control of eye saccades in reading. Vision Research, 14, 273-284.

Bridgeman, B. , STARK L. (1979). Omnidirectional increase in threshold for image shifts during saccadic eye movements. Perception \& Psychophysics, 25, 241-243.

BroOKs, B. A., \& FuCHS, A. F. (1975). Influence of stimulus parameters on visual sensitivity during saccadic eye movements. Vision Research, 15, 1389-1398. 
Brooks, B. A., IMPELMAN, D. M., \& LUM, J. T. (1980). Influence of background luminance on visual sensitivity during saccadic eye movements. Experimental Brain Research, 40, 322-329.

Burr, D. C., Holt, J., Jonstone, J, R., \& Ross, J. R. (1982). Selective depression of motion sensitivity during saccades. Joumal of Physiology, 333, 1-15.

Camprell, F. W., \& Wurtz, R. H. (1978). Saccadic omission: Why we do not see a grey out during a saccadic eye movement. Vision Research, 18, 1297-1303.

Coren, S. , \& HoENig, P. (1972). Effect of non-target stimuli upon length of voluntary saccades. Perceptual \& Motor Skills, 34, 499-508.

Eizenman, M., Frecker, R. C., \& Hallett, P. (1984). Precise noncontacting measurement of eye movements using corneal reflex. $\mathrm{Vi}$ sion Research, 15, 719-722.

Findlay, J. M. (1982). Global visual processing for saccadic eye movements. Vision Research, 22, 1033-1045.

Fischer, B., \& BOCH, R. (1983). Saccadic eye movements after ex tremely short reaction time in monkey. Brain Research, 260, 21-26.

Fischer, B., \& Breitmeyer, B. (1987). Mechanisms of visual attention revealed by saccadic eye movements. Neuropsychologia, 25, 73-83.

FisCHER, B., \& RAMSPERGER, E. (1984). Human express saccades: Extremely short reaction times of goal directed eye movements. Brain Research, 260, 21-26.

Hallett, P. E. (1978). Primary and secondary saccades to goals defined by instructions. Vision Research, 18, 1279-1296.

Hallett, P. E., \& Lightstone, A. D. (1976). Saccadic eye move ments towards stimuli triggered by prior saccades. Vision Research 16, 99-106.

Henson, D. B. (1979). Investigation into corrective saccadic eye movements for refixation amplitudes of 10 degrees and below. Vision Re search, 19, 57-61

INHOFF, A. W. (1984). Two stages of word processing during eye fixations in the reading of prose. Journal of Verbal Learming \& Verbal Behavior, 20, 641-655.

IsHIDA, T., \& IKEDA, M. (1989). Temporal properties of information extraction in reading studied by a text-mask replacement technique. Journal of the Optical Society of America, 6, 1624-1632.

KLeiN, G. A., \& KURKowski, F. (1974). Effect of task demands on relationships between eye movements and sentence complexity. Perceptual \& Motor Skills, 39, 463-466.

Komoda, M. K., Festinger, L., Phillips, L. J., Duckman, R. H., \& Young, R. A. (1973). Some observations concerning saccadic eye movements. Vision Research, 13, 1009-1020.

Levy-Schoen, A., \& Blanc-Garin, J. (1974). On oculomotor programming and perception. Brain Research, 71, 443-450.

LoFTus, G. R. (1972). Eye fixations and recognition memory for pictures. Cognitive Psychology, 3, 525-551.

LofTus, G. R. (1983). Eye fixation on text and scenes. In K. Rayner (Ed.), Eye movement in reading (pp. 359-376). New York: Academic Press.

Loftus, G. R., \& MACkworTh, N. H. (1978). Cognitive determinants of fixation location during picture viewing. Journal of Experimental Psychology: Human Perception \& Performance, 4, 565-572.

MAcKaY, D. M. (1970). Elevation of visual threshold by displacement of retinal image. Nature, 225, 90-92.

Mackworth, N. H., \& Morand, A. J. (1967). The gaze selects in formative details within pictures. Perception \& Psychophysics, 2, 547-552.

Malt, B. C., \&eamon, J. G. (1978). Peripheral and cognitive components of eye guidance in filled-space reading. Perception \& Psychophysics, 23, 399-402.

Matin, E. (1974). Saccadic suppression: A review and an analysis. Psychological Bulletin, 81, 899-917.

Matin, E., Clymer, A., \& Matin, L. (1972). Metacontrast and saccadic suppression. Science, 178, 179-182.

Matin, L., Matin, E., \& Parce, D. G. (1969). Visual perception of direction when voluntary saccades occur: I. Relation of visual direc- tion of a fixation target extinguished before a saccade to a flash presented during the saccade. Perception \& Psychophysics, 5, 65-80.

MCConkIE, G. W. (1983). Eye movements and perception during reading. In K. Rayner (Ed.), Eye movement in reading (pp. 65-96). New York: Academic Press.

MCConkie, G. W., Underwood, N. R., Zola, D., \& Wolverton, G. S. (1985). Some temporal characteristics of processing during reading. Journal of Experimental Psychology: Human Perception \& Performance, 11, 168-186.

MofFITT, K. (1980). Evaluation of the fixation duration in visual search Perception \& Psychophysics, 27, 370-372.

Morrison, R. E. (1984). Manipulation of stimulus onset delay in reading: Evidence for parallel programming of saccades. Joumal of $E x$ perimental Psychology: Human Perception \& Performance, 10. 667-682.

Navon, D. (1977). Forest before trees: The precedence of global features in visual perception. Cognitive Psychology, 9, 353-383.

Navon, D., \& Norman, J. (1983). Does global precedence really depend on visual angle? Joumal of Experimental Psychology: Human Perception \& Performance, 9, 955-965.

O'REGAN, K. (1979). Saccade size control in reading: Evidence for the linguistic control hypothesis. Perception \& Psychophysics, 25, 501-509.

Ottes, F. P., Van Gisbergen, J. A. M., \& Eggermont, J. J. (1984). Metrics of saccade responses to visual double stimuli: Two different modes. Vision Research, 24, 1169-1179.

OtTes, F. P., Van Gisbergen, J. A. M., \& Eggermont, J. J. (1985). Latency dependence of colour-based target vs. nontarget discrimination by the saccadic system. Vision Research, 25, 849-862.

Pollatsek, A., \& Rayner, K. (1982). Eye movement control in reading: The role of word boundaries. Journal of Experimental Psychology: Human Perception \& Performance, 8, 817-833.

RAYNER, K. (1975). The perceptual span and peripheral cues in reading. Cognitive Psychology, 7, 65-81.

RAYNER, K. (1977). Visual attention in reading: Eye movements reflect cognitive processes. Memory \& Cognition, 5, 443-448

RAYNER, K. (1978). Eye movement in reading and information processing. Psychological Bulletin, 85, 618-660.

RAYNER, K. (1983). The perceptual span and eye movement control during reading. In K. Rayner (Ed.), Eye movement in reading (pp. 97120). New York: Academic Press

Rayner, K., Inhoff, A. W., Morrison, R. E., Slowiaczek, M. L., \& Bertera, J. H. (1981). Masking of foveal and parafoveal vision during eye fixation in reading. Journal of Experimental Psychology: Human Perception \& Performance, 7, 167-179.

Rayner, K., \& Pollatsek, A. (1981). Eye movement control during reading: Evidence for direct control. Quarterly Joumal of Experimental Psychology, 33A, 351-373.

Rayner, K., Slowiaczek, M. L., Clufton, C., JR., \& Bertera, J. H (1983). Latency of sequential eye movements: Implications for reading. Journal of Experimental Psychology: Human Perception \& Performance, 9, 912-922

Riggs, L. A., Volkmann, F. C., Moore, R. K., \& Ellicot, A. G. (1982). Perception of suprathreshold stimuli during saccadic eye movement. Vision Research, 12, 423-428.

Ross, L. E., \& Ross, S. M. (1980). Saccade latency and warning signals: Stimulus onset, offset, and change as warning events. Perception \& Psychophysics, 27, 251-257.

Ross, S. M., \& Ross, L. E. (1981). Saccade latency and warning sig nals: Effects of auditory and visual stimulus onset and offset. Perception \& Psychophysics, 29, 429-437.

Salthouse, T. A., \& Elus, C. L. (1980). Determination of eye-fixation duration. American Journal of Psychology, 93, 207-234.

Shiolr, S., \& Cavanagh, P. (1989). Saccadic suppression of low-level motion. Vision Research, 29, 915-928.

ShIOIRI, S., \& IKEDA, M. (1989). Useful resolution for picture perception as a function of eccentricity. Perception, 18, 347-361.

van Asten, W. N. J. C., Gielen, C. C. A. M., \& De Winkel, 
M. E. M. (1988). The effect of isoluminant and isochromatic stimuli on latency and amplitude of saccades. Vision Research, 28, 827-840.

VAUGHAN, J. (1982). Control of fixation duration in visual search and memory search: Another look. Journal of Experimental Psychology: Human Perception \& Performance, 8, 709-723.

Vaughan, J., \& Graefe, T. M. (1977). Delay of stimulus presentation after the saccade in visual search. Perception \& Psychophysics, 22, 201-205.

VolkmanN, F. C. (1986). Human visual suppression. Vision Research, 26, 1401-1416.

WEBER, R. B., \& DAROFF, R. B. (1971). The metrics of horizontal saccadic eye movements in normal humans. Vision Research, 11, $921-928$.
Weber, R. B., \& Daroff, R. B. (1972). Corrective movements following refixation saccades: Type and control system analysis. Vision Research, 12, 467-475.

Wheeless, L., JR., Boynton, R., \& Cohen, G. (1966). Eye-movement responses to step and pulse-step stimuli. Joumal of the Optical Society of America, 56, 956-960.

Wolverton, G. S., \& Zola, D. (1983). The temporal characteristics of visual information extraction during reading. In K. Rayner (Ed.), Eye movement in reading (pp. 43-61). New York: Academic Press.

(Manuscript received January 23, 1991; revision accepted for publication August 14, 1992.) 